\title{
Stabilization of Wind Turbine Generator System by STATCOM
}

\author{
S.M. Muyeen Student Member (Kitami Institute of Technology, muyeen@pullout.elec.kitami-it.ac.jp) \\ Mohammad Abdul Mannan Student Member (Kitami Institute of Technoloy) \\ Mohd. Hasan Ali Member (Kitami Institute of Technoloy) \\ Rion Takahashi Member (Kitami Institute of Technology) \\ Toshiaki Murata Member (Kitami Institute of Technology) \\ Junji Tamura Member (Kitami Institute of Technology)
}

Keywords: fuzzy logic controller (FLC), multi-mass shaft model, pitch controller, PWM voltage source converter (VSC), STATCOM, three level inverter, wind turbine generator system (WTGS)

Recently voltage-source or current-source inverter based various FACTS devices have been used for flexible power flow control, secure loading, damping of power system oscillation and even for the stabilization of wind energy generation. In this paper, we propose the static synchronous compensator (STATCOM) based on voltage source converter (VSC) PWM technique to stabilize grid connected wind generator system. A simple control strategy of STATCOM is adopted where only measurement of rms voltage at the wind generator terminal is needed, i.e. there is no need of reactive power measurement. Fuzzy logic controller rather than conventional PI controller is proposed as the control methodology of STATCOM. Multi-mass shaft model of wind turbine generator system (WTGS) is also considered as it has a big influence on the transient performance of WTGS. Transient performance of STATCOM connected WTGS is compared also with that of pitch controlled WTGS. Moreover, the steady state performance of STATCOM connected WTGS is analyzed. It is reported that STATCOM can reduce the voltage fluctuation significantly. Finally STATCOM is applied to a wind park model with multiple wind generators. Comprehensive results are presented to assess the performance of STATCOM connected WTGS.

The model system used for simulation of transient stability is shown in Fig. 1. In this work three-level STATCOM is considered. The one pole structure of three level GTO inverter is shown in Fig. 2(a). The GTO switching table and control methodology of STATCOM are shown in Fig. 2(b) and Fig. 2(c) respectively. The aim of the control is to maintain constant voltage magnitude at the induction generator terminal, under system disturbances. The control is based on PWM technique where only terminal voltage measurement is needed. An error signal is obtained by comparing reference voltage with rms voltage of induction generator terminal. A PI or Fuzzy controller progresses the error signal and generates the re-

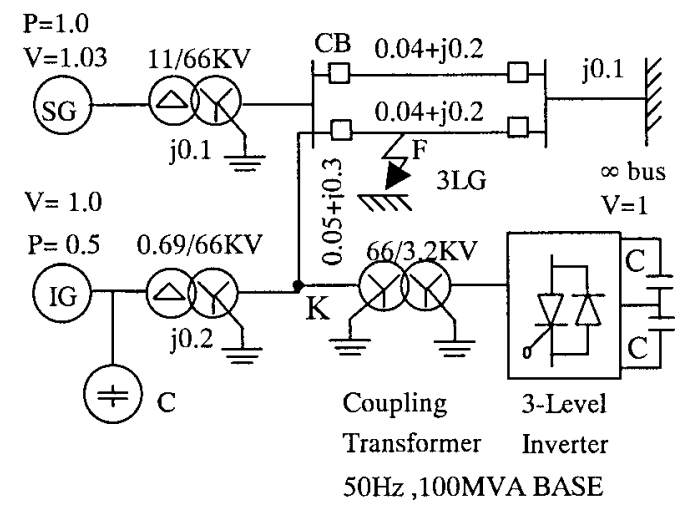

Fig. 1. Model system

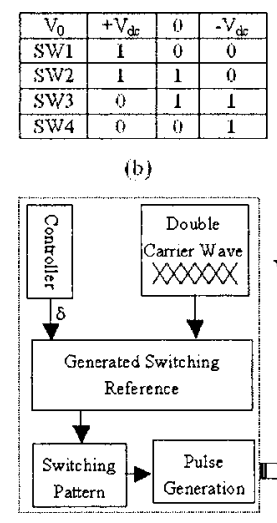

(c)

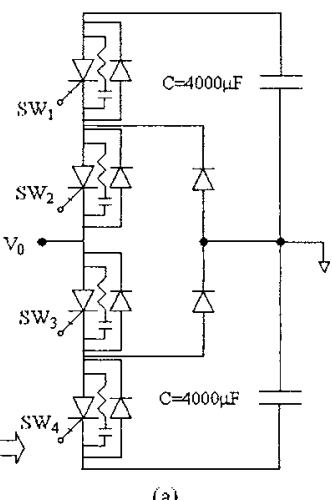

(a)
Fig. 2. Schematic diagram of STATCOM switching circuit: (a) one pole structure, (b) the switching table, (c) pulse generation system

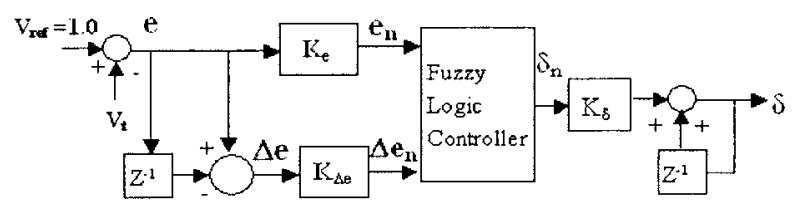

Fig. 3. Fuzzy logic controller

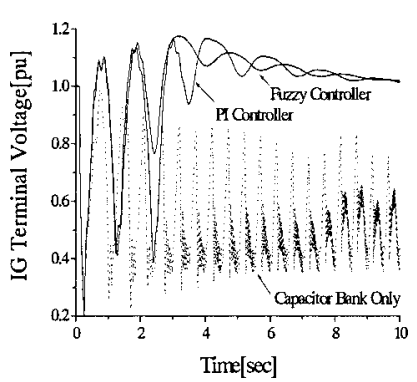

Fig. 4. Terminal voltage of IG with \& without STATCOM (two-mass)

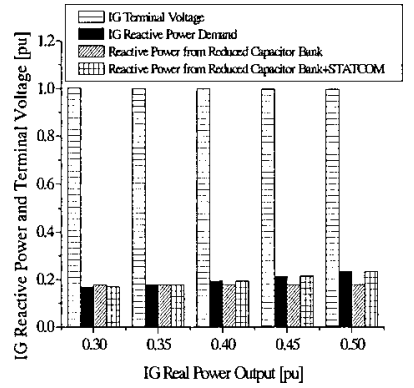

Fig. 5. Steady state characteristics with STATCOM quired angle $\delta$ to drive the error to zero, i.e. the induction generator terminal voltage is brought back to the reference voltage. The control methodology of STATCOM by Fuzzy logic controller is shown in Fig. 3.

Figure 4 shows the terminal voltage of IG after a $3 \mathrm{LG}$ fault with and without STATCOM. Figure 5 shows that STATCOM can maintain the steady state performance also. So, our proposed FLC controlled STATCOM can enhance the transient and steady state performance of grid connected WTGS. 


\section{Stabilization of Wind Turbine Generator System by STATCOM}

$\begin{array}{ll}\text { S.M. Muyeen* } & \text { Student Member } \\ \text { Mohammad Abdul Mannan* } & \text { Student Member } \\ \text { Mohd. Hasan Ali* } & \text { Member } \\ \text { Rion Takahashi* } & \text { Member } \\ \text { Toshiaki Murata* } & \text { Member } \\ \text { Junji Tamura* } & \text { Member }\end{array}$

Recently voltage-source or current-source inverter based various FACTS devices have been used for flexible power flow control, secure loading, damping of power system oscillation and even for the stabilization of wind energy generation. In this paper, we propose the static synchronous compensator (STATCOM) based on voltage source converter (VSC) PWM technique to stabilize grid connected wind generator system. A simple control strategy of STATCOM is adopted where only measurement of rms voltage at the wind generator terminal is needed. Fuzzy logic controller rather than conventional PI controller is proposed as the control methodology of STATCOM. Multi-mass shaft model of wind turbine generator system (WTGS) is also considered as shaft modeling has a big influence on the transient performance of WTGS. Transient performance of STATCOM connected WTGS is compared also with that of pitch controlled WTGS. Both symmetrical and unsymmetrical faults are analyzed. Moreover, the steady state performance of STATCOM connected WTGS is analyzed. It is reported that STATCOM can reduce the voltage fluctuation significantly. Finally STATCOM is applied to a wind park model with multiple wind generators. Comprehensive results are presented to assess the performance of STATCOM connected WTGS, where the simulations have been done by PSCAD/EMTDC.

Keywords: fuzzy logic controller, multi-mass shaft model, pitch controller, PWM voltage source converter, STATCOM, wind generator

\section{Introduction}

Due to clean and economical energy generation, a huge number of wind farms are going to be connected with the existing network in the near future ${ }^{(1)}$. Induction generator (IG) is widely used as wind generator due to its simple, rugged and maintenance free construction. But as it has some stability problems, it is necessary to investigate the stability aspect of induction generator when connected to the power grid $^{(2)}$. Recently voltage-source or current-source inverter based flexible AC transmission systems (FACTS) devices such as static var compensator (SVC), static synchronous compensator (STATCOM), dynamic voltage restorer (DVR), solid state transfer switch (SSTS) and unified power flow controller (UPFC) have been used for flexible power flow control, secure loading and damping of power system oscillation $^{(3)-(5)}$. Some of those can be used to improve transient and dynamic stability of wind generator. SVC is reported with synchronous generator in Ref. (6) and with induction generator in Ref. (7) for reactive power compensation. But STATCOM has somewhat better performance compared to SVC for reactive power compensation, which is reported clearly in Refs. (8) (9). Modeling of voltage source converter based STATCOM are discussed in Refs. (10)-(22). STATCOM

\footnotetext{
* Department of EEE, Kitami Institute of Technology

165, Koen-cho, Kitami 090-8507
}

with multi-machine power system is discussed in Ref. (12). In Ref. (10)-(12) (14) (18)-(22), two level VSC based STAT$\mathrm{COM}$ is discussed. But for high voltage application, at least three-level inverter is the right choice for VSC based STAT$\mathrm{COM}^{(15)-(17)}$. Some authors have reported valuable studies on STATCOM connected with WTGS ${ }^{(18)-(21)}$. In Ref. (18), steady state reactive power control and islanding performance of induction generator are discussed. In Ref. (19), it is reported that STATCOM can recover terminal voltage of wound rotor induction generator after the fault clearance. But as only induction generator is connected to the network, the effect of STATCOM on the rest of the system is not presented there. Flicker mitigation of wind generator by using STATCOM is discussed in Refs. (20) (21).

Though a lot of works with STATCOM are reported in power system literature, stability analysis of WTGS by using STATCOM is not sufficient enough. In our previous work $^{(22)}$, stability of single WTGS connected to a grid was discussed by using a two-level VSC based STATCOM. In the present paper, we propose three level STATCOM based on voltage source converter PWM technique. In the previous works with STATCOM and WTGS ${ }^{(18)-(22)}$, multi-mass shaft model was not considered. But in Ref. (23), it is reported that for transient stability analysis of WTGS, multi-mass shaft model should be considered, though any types of reactive power compensation tools is not used there. Reactive power compensation of wind generator with static shunt capacitor 
is reported in Ref. (24), where multi-mass shaft model was considered. But in that literature fault-clearing time was emphasized.

In this work, application of STATCOM is presented to enhance steady state and transient performances of grid connected WTGS. A simple control strategy of STATCOM is adopted where only measurement of rms voltage at the IG terminal is needed. Then as the control system of STATCOM the performance of conventional PI controller and fuzzy logic controller (FLC) are investigated. The voltage sag and swell improvement of WTGS is analyzed. It is presented that induction generator steady state capacitor value can be reduced by certain percentage from the rated value where the rest of the reactive power drawn by induction generator at steady state will be supplied by the STATCOM. It is also reported that the multi-mass shaft model of WTGS has a significant effect on the dynamic characteristic of grid connected wind generator controlled by STATCOM. This is one of the novel features of this work. Transient performance of STATCOM controlled WTGS is compared with that of pitch controlled WTGS. Stabilization of multiple wind generators by STATCOM is considered also. Both symmetrical and unsymmetrical faults are analyzed. Moreover, it is presented that STATCOM can reduce wind generator voltage fluctuation under variable wind speed, i.e. STATCOM can improve the power quality of WTGS. Finally, it is shown that besides WTGS, STATCOM can also enhance the stability of entire power system.

\section{Wind Turbine Modeling}

The mathematical relation for the mechanical power extraction from the wind can be expressed as follows:

$$
\mathrm{P}_{\mathrm{w}}=0.5 \rho \pi \mathrm{R}^{2} \mathrm{~V}_{\mathrm{w}}^{3} \mathrm{C}_{\mathrm{P}}(\lambda, \beta) .
$$

Where, $\mathrm{P}_{\mathrm{w}}$ is the extracted power from the wind, $\rho$ is the air density $\left[\mathrm{kg} / \mathrm{m}^{3}\right], \mathrm{R}$ is the blade radius $[\mathrm{m}], \mathrm{V}_{\mathrm{w}}$ is the wind speed $[\mathrm{m} / \mathrm{s}]$ and $C_{p}$ is the power coefficient which is a function of both tip speed ratio, $\lambda$, and blade pitch angle, $\beta$ [deg]. In this work, the $\mathrm{Cp}$ equation as shown below has been taken from Ref. (25).

$$
\begin{aligned}
& \lambda=\frac{\mathrm{V}_{\mathrm{w}}}{\omega_{\mathrm{B}}} \ldots \ldots \ldots \ldots \ldots \ldots \ldots \ldots \ldots \ldots \\
& \mathrm{C}_{\mathrm{p}}=\frac{1}{2}\left(\lambda-0.022 \beta^{2}-5.6\right) \mathrm{e}^{-0.17 \lambda} .
\end{aligned}
$$

Where, $\omega_{\mathrm{B}}$ is the rotational speed $[\mathrm{rad} / \mathrm{s}]$. The $\mathrm{Cp}-\lambda$ curves

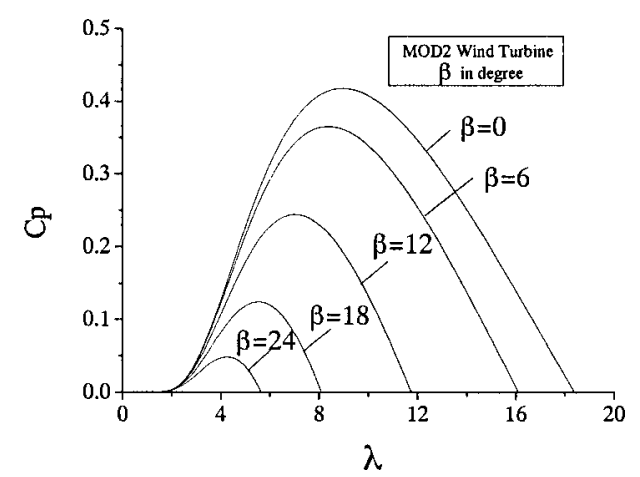

Fig. 1. $C_{P}-\lambda$ curves for different pitch angles are shown in Fig. 1 for different values of $\beta$.

Wind turbine torque, $\mathrm{T}_{\mathrm{wt}}$ can be expressed as follows:

$$
\mathrm{T}_{\mathrm{wt}}=\mathrm{P}_{\mathrm{w}} / \omega_{\mathrm{B}}
$$

In this analysis, one-mass lumped and two-mass shaft models are considered to express the drive train mechanics. The detailed discussion of two-mass shaft model is available in Ref. (23) (26)-(28). The drive train parameters are presented in Table 2, where, $\mathrm{H}_{\mathrm{wt}}, \mathrm{H}_{\mathrm{g}}$, and $\mathrm{K}_{\mathrm{w}}$ are turbine inertia constant, generator inertia constant, and shaft spring constant respectively. Damping is disregarded throughout the analysis.

\section{Wind Turbine Modeling}

Though the STATCOM configuration often consists of a two-level VSC, a dc energy storage device, and a coupling transformer connected in shunt with the ac system ${ }^{(22)}$, threelevel STATCOM is considered in this work. In order to generate high output voltage, VSC needs to use power semiconductor devices with high breakdown voltage. Due to the limitation of state-of-the-art semiconductor switch technology, the power voltage rating is generally around $6 \mathrm{KV}$, with mainstream switch voltage rating at $4.5 \mathrm{KV}$. There are two ways to increase the output voltage further, one is to use device series connection, the other is to use multilevel converter. Although series connection of power semiconductor devices is a proven technology, there is still restriction to maximum allowable number of units. In this work, three-level inverter is used to increase the output voltage. The three-level inverter has the advantages that the blocking voltage of each switching device is one half of dc-link voltage, in contrast to the full dc-link voltage in case of the two-level inverter, and the harmonic contents of three-level inverter output voltage are much less than those of two-level one, at the same switching frequency ${ }^{(15)}$. The three-level inverter can be operated at lower switching frequency $\left(\mathrm{f}_{\mathrm{sw}}<500 \mathrm{~Hz}\right)$ without excessive harmonic currents and can be coupled directly to $3.2 \mathrm{KV}$ ac grid using 4.5 KV GTO's.

The one pole structure of three level GTO inverter is shown in Fig. 2(a). The GTO switching table and control methodology of STATCOM are shown in Fig. 2(b) and Fig. 2(c) respectively. The snubber circuit resistance and capacitance values in Fig. 2(a) are $5000 \Omega$ and $0.05 \mu \mathrm{F}$ respectively. The VSC converts the dc voltage across the storage device into a set of three-phase ac output voltages. These voltages are in phase and coupled with the ac system through the reactance of the coupling transformer. Suitable adjustment of phase and magnitude of the STATCOM output voltage allows effective control of power exchange between the STATCOM and the ac system. In this paper, STATCOM is used to regulate the induction generator terminal voltage. So, the aim of the control is to maintain constant voltage magnitude at the induction generator terminal, under system disturbances. The control is based on PWM technique where only terminal voltage measurement is needed. An error signal is obtained by comparing the reference voltage with the rms voltage of induction generator terminal. A PI or Fuzzy controller progresses the error signal and generates the required angle $\delta$ to drive the error to zero, i.e. the induction generator terminal voltage is brought back to the reference voltage. In the PWM generators, the 
sinusoidal reference signal is phase modulated by means of the angle $\delta$. The modulated signal is compared with triangular carrier signal in order to generate the switching signals for the GTO switched VSC. High switching frequencies can be used to improve the efficiency of the converter, without incurring significant switching losses. In our simulation the switching frequency is chosen $450 \mathrm{~Hz}$ and amplitude modulation index is chosen $1.0 \mathrm{pu}$, in order to obtain the highest fundamental voltage component at the controller output ${ }^{(14)}$. The modulated angle $\delta$ is applied to the PWM generators in phase A. The angles for phases B and $\mathrm{C}$ will be shifted by 240 and 120 degrees respectively. The control methodology of STATCOM is discussed below.

3.1 PI Controller Design The classical PI controller finds extensive application in industrial control. The structure of continuous time PI controller is shown in Fig. 3, where e (error signal of terminal voltage of IG) is the input and $\delta$ is the output of the PI controller. $K_{P}$ and $T_{i}$ represent the proportional gain and integration time constant respectively. The values of $K_{P}$ and $T_{i}$ are chosen 105.0 and 0.025 respectively when one-mass lumped model of WTGS is considered. When two-mass shaft model of WTGS is considered, the values of $K_{P}$ and $T_{i}$ are chosen 25.0 and 0.012 respectively. It is important to note here that the parameters of PI controller for all simulation cases are determined by trial-and-error approach in order to obtain the best performance.

3.2 Fuzzy Logic Controller Design The proposed FLC system as shown in Fig. 4 is used to find out the angle, $\delta$, in the control block from the error signal, e, and change of error signal, $\triangle \mathrm{e}$. The FLC is explained in the following:

3.2.1 Fuzzification To design the proposed FLC, the

\begin{tabular}{|c|c|c|c|}
\hline $\mathrm{V}_{0}$ & $+\mathrm{V}_{\mathrm{dc}}$ & 0 & $-\mathrm{V}_{\mathrm{dc}}$ \\
\hline $\mathrm{SW} 1$ & 1 & 0 & 0 \\
\hline SW2 & 1 & 1 & 0 \\
\hline SW3 & 0 & 1 & 1 \\
\hline SW4 & 0 & 0 & 1 \\
\hline
\end{tabular}

(b) The switching table

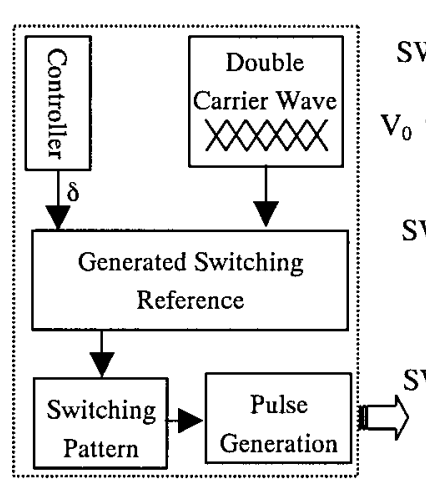

(c) Pulse generation system

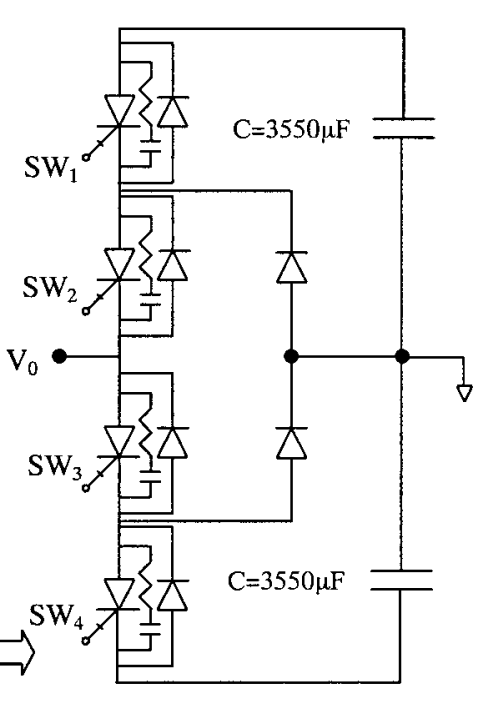

(a) One pole structure
Fig. 2. Schematic diagram of STATCOM switching circuit

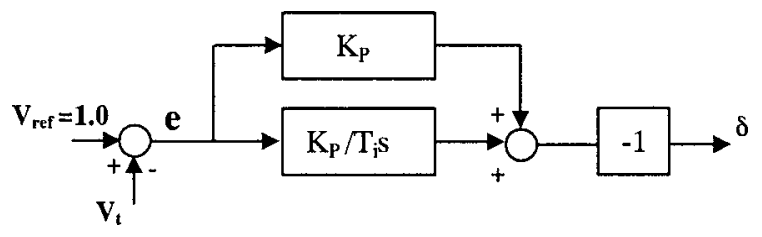

Fig. 3. PI controller error signal, $e(k)$, and change of error signal, $\Delta e(k)$ are considered as the controller inputs. The angle, $\delta$, is considered as the controller output, which is actually modulated angle. For convenience, the inputs and output of the FLC are scaled with coefficients $K_{\mathrm{e}}, K_{\Delta \mathrm{e}}$, and $K_{\delta}$ respectively. These scaling factors can be constants or variables and play an important role for FLC design in order to achieve a good response in both transient and steady states. In this work, these scaling factors are considered as constant for the simplicity of controller design, and are selected by trial-and-error in order to obtain the best system performance. The values of $K_{\mathrm{e}}$, $K_{\Delta \mathrm{e}}$ and $K_{\delta}$ are chosen 1.0, 7500 and 0.065 respectively for one-mass WTGS. For two mass shaft model $K_{\mathrm{e}}, K_{\Delta \mathrm{e}}$ and $K_{\delta}$ are chosen 1.0, 500 and 0.025 respectively. In Fig. $4, \mathrm{Z}^{-1}$ represents one sampling time delay. The triangular membership functions with overlap used for the input and output fuzzy sets are shown in Fig. 5 in which the linguistic variables are represented by NB (Negative Big), NS (Negative Small), Z (Zero), PS (Positive Small), and PB (Positive Big). The grade of input membership functions can be obtained from

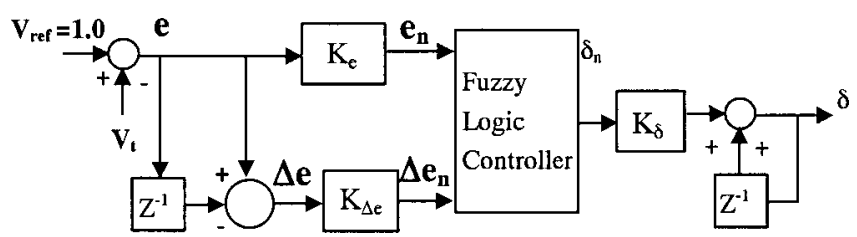

Fig. 4. Fuzzy logic controller
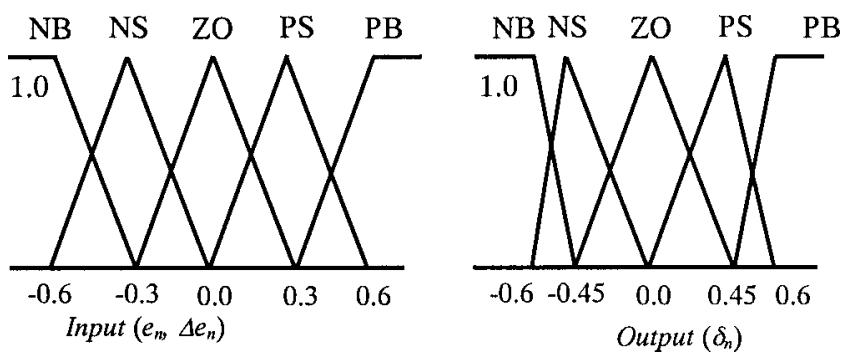

(a) For one-mass WTGS
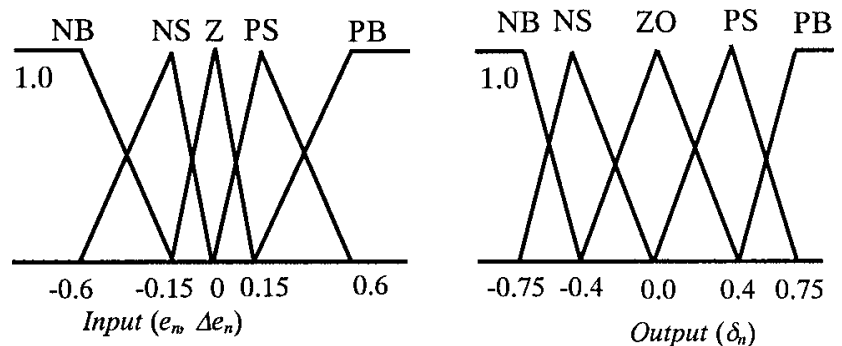

(b) For two-mass WTGS

Fig. 5. Fuzzy sets and their corresponding memberships functions

Table 1. Fuzzy rule table for both one-mass \& two-mass WTGS

\begin{tabular}{|c|c|c|c|c|c|c|}
\hline \multicolumn{2}{|c|}{$\delta_{\mathrm{n}}$} & \multicolumn{5}{|c|}{$\Delta \mathrm{e}_{\mathrm{n}}$} \\
\cline { 2 - 7 } \multicolumn{2}{|c|}{} & NB & NS & ZO & PS & PB \\
\hline \multirow{4}{*}{$\approx$} & NB & PB & PB & PS & PS & ZO \\
\cline { 2 - 7 } & NS & PB & PS & PS & ZO & NS \\
\cline { 2 - 7 } & ZO & PS & PS & ZO & NS & NS \\
\cline { 2 - 7 } & PS & PS & ZO & NS & NS & NB \\
\cline { 2 - 7 } & PB & ZO & NS & NS & NB & NB \\
\hline
\end{tabular}


the following equation ${ }^{(29)}$.

$$
\mu(\mathrm{x})=[\mathrm{w}-2|\mathrm{x}-\mathrm{m}|] / \mathrm{w}
$$

Where, $\mu(x)$ is the value of grade of membership, $\mathrm{w}$ is the width, $\mathrm{m}$ is the coordinate of the point at which the grade of membership is 1 , and $\mathrm{x}$ is the value of the input variable.

3.2.2 Rule base The fuzzy mapping of the input variables to the output is represented by IF-THEN rules of the following forms:

$$
\begin{aligned}
& \mathrm{IF}\left\langle e_{n} \text { is } \mathrm{NB}\right\rangle \text { and }\left\langle\Delta e_{n} \text { is } \mathrm{NB}\right\rangle \text { THEN }\left\langle\delta_{n} \text { is } \mathrm{PB}\right\rangle \\
& \mathrm{IF}\left\langle e_{n} \text { is } \mathrm{PB}\right\rangle \text { and }\left\langle\Delta e_{n} \text { is } \mathrm{PB}\right\rangle \text { THEN }\left\langle\delta_{n} \text { is } \mathrm{NB}\right\rangle
\end{aligned}
$$

The entire rule base is given in Table 1 . There are total 25 rules to achieve desired angle, $\delta$.

3.2.3 Inference \& defuzzification In this work, for the inference mechanism, Mamdani's max-min (or sumproduct) ${ }^{(29)}$ method is used. The center of gravity method ${ }^{(29)}$ is used for defuzzification to obtain $\delta_{\mathrm{n}}$, which is given by the following equation:

$$
\delta_{\mathrm{n}}=\sum_{\mathrm{i}=1}^{\mathrm{N}} \mu_{\mathrm{i}} \mathrm{C}_{\mathrm{i}} / \sum_{\mathrm{i}=1}^{\mathrm{N}} \mu_{\mathrm{i}}
$$

Where, $\mathrm{N}$ is the total number of rules, $\mu_{\mathrm{i}}$ is the membership grade for $i$-th rule and $C_{i}$ is the coordinate corresponding to the respective output or consequent membership function $\left[\mathrm{C}_{\mathrm{i}} \in\{-0.6,-0.45,0,0.45,0.6\}\right.$ for one-mass WTGS and $C_{i} \in\{-0.75,-0.4,0,0.4,0.75\}$ for two-mass WTGS]. The actual modulated angle, $\delta$, can be found out by multiplicating $\delta_{\mathrm{n}}$ by the scaling factor $\mathrm{K}_{\delta}$.

\section{Simulation Results}

Figure 6 shows the model system used for the simulation of the transient stability. The system base is 100 MVA. Here, one wind farm (Induction generator, IG) is connected with the network via a transformer and short transmission line. A capacitor bank has been used for reactive power compensation at steady state ${ }^{(2)}$. The value of capacitor $\mathrm{C}$ is chosen so that the power factor of the wind power station becomes unity. The AVR (Automatic Voltage Regulator) and GOV (Governor) control system models as shown in Fig. 7 and Fig. 8 respectively for the synchronous generator have been included in the simulation. Generator parameters are shown in Table 2. The initial values used in the simulation are expressed in Table 3.

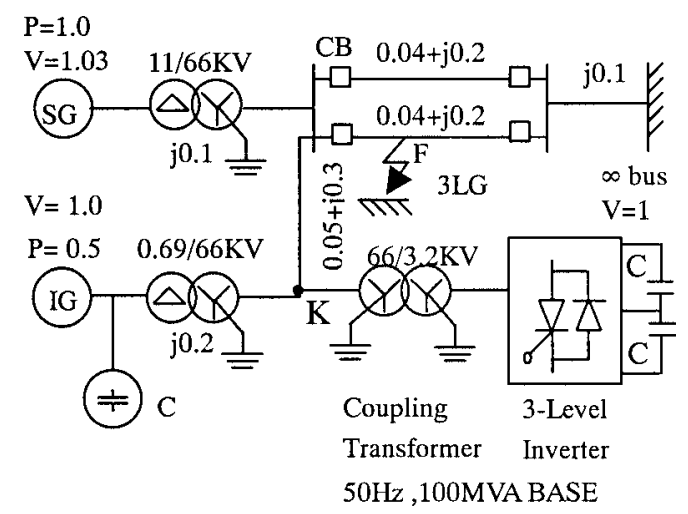

Fig. 6. Model system
The STATCOM is connected at point $\mathrm{K}$ in Fig. 6. In this paper, the STATCOM rating is considered as 50 MVA. A single line diagram of the STATCOM is shown schematically in Fig. 9. Considering the practical viewpoints, the overall solid-state power circuit combines four three-phase inverter modules, each with nominal rating of $12.5 \mathrm{MVA}$, with a nominal phase-to-phase ac voltage of $3.2 \mathrm{KV}$ and a DC link voltage of $6.5 \mathrm{KV}$. The inverters are coupled to the $66 \mathrm{KV}$ line by a single step down transformer with 0.2 p.u leakage reactance (base value $100 \mathrm{MVA}$ ). Inverter linking reactance is 0.036 p.u (base value $100 \mathrm{MVA}$ ). DC capacitor value of each inverter module is $3550 \mu \mathrm{F}$. The main power semiconductor devices incorporated in the converter design are gate turn-off thyristors (GTO's), rated at $6 \mathrm{kV}, 6 \mathrm{KA}$. As these devices are arranged in each module, forming a three-level inverter circuits, the voltage stress of each switching device is clamped to one half of the dc-link voltage $(3.25 \mathrm{KV})$, whereas full dclink voltage for two level conventional inverter is $6.5 \mathrm{KV}$ and thus the power devices could be fully utilized in high voltage range. In this work, the continuous rating of the STATCOM is set to 9.6 percentage of its full rating at rated wind speed, for which the rated reactive power demand of IG is ensured and the GTO current rating also doesn't exceed 1.0 KA, which is below the rated current rating. The steady state and

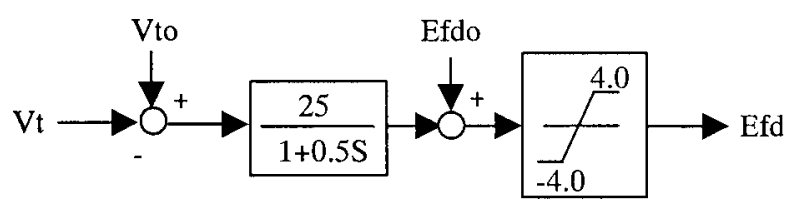

Fig. 7. AVR model

\begin{tabular}{|c|c|c|c|}
\hline \multicolumn{2}{|c|}{ SG } & \multicolumn{2}{|c|}{ IG } \\
\hline MVA & 100 & MVA & 50 \\
\hline $\mathrm{ra}(\mathrm{pu})$ & 0.003 & $\mathrm{Il}(\mathrm{pu})$ & 0.01 \\
\hline $\mathrm{xa}(\mathrm{pu})$ & 0.13 & $\mathrm{x} 1(\mathrm{pu})$ & 0.1 \\
\hline $\mathrm{Xd}(\mathrm{pu})$ & 1.2 & $\mathrm{X}_{\mathrm{mu}}(\mathrm{pu})$ & 3.5 \\
\hline $\mathrm{Xg}(\mathrm{pu})$ & 0.7 & $\mathrm{I} 21(\mathrm{pu})$ & 0.035 \\
\hline $\mathrm{Xd}(\mathrm{pu})$ & 0.3 & $\mathrm{x} 21$ (pu) & 0.030 \\
\hline$X d^{\prime \prime}(p u)$ & 0.22 & $\mathrm{r} 22(\mathrm{pu})$ & 0.014 \\
\hline $\mathrm{Xq} \mathrm{q}^{\prime \prime}(\mathrm{pu})$ & 0.25 & $\mathrm{x} 22(\mathrm{pu})$ & 0.098 \\
\hline Tdo $(\mathrm{sec})$ & 5.0 & $\mathrm{H}_{\mathrm{wt}}(\mathrm{sec})$ & 3.0 \\
\hline Tdo" $(\mathrm{sec})$ & 0.04 & $\mathrm{H}_{\mathrm{g}}(\mathrm{sec})$ & 0.3 \\
\hline Tqo $(\mathrm{sec})$ & 0.05 & $\mathrm{~K}_{w}(\mathrm{pu})$ & 90 \\
\hline $\mathrm{H}(\mathrm{sec})$ & 2.5 & & \\
\hline
\end{tabular}

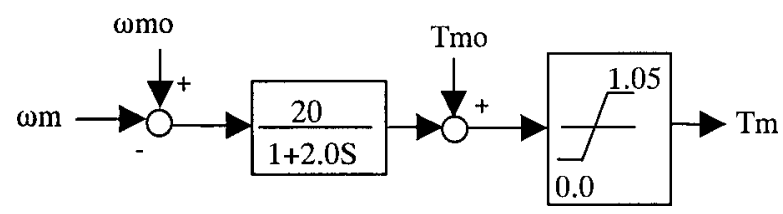

Fig. 8. GOV model

\begin{tabular}{|c|c|c|c|c|c|c|c|c|}
\hline & \multicolumn{2}{|c|}{ Condition1 } & \multicolumn{6}{|c|}{ Condition2 } \\
\hline & SG & IG & SG & IG1 & IG2 & IG3 & IG4 & IG5 \\
\hline $\mathrm{P}(\mathrm{pu})$ & 1.0 & 0.50 & 1.0 & 0.10 & 0.095 & 0.09 & 0.085 & 0.08 \\
\hline V(pu) & 1.03 & 0.999 & 1.03 & 1.017 & 1.019 & 1.022 & 1.024 & 1.026 \\
\hline $\mathrm{Q}(\mathrm{pu})$ & 0.334 & $\begin{array}{r}0.00 \\
\left(.239^{*}\right)\end{array}$ & 0.289 & $\begin{array}{r}0.001 \\
\left(.048^{\circ}\right)\end{array}$ & $\begin{array}{r}0.003 \\
\left(.046^{*}\right)\end{array}$ & $\begin{array}{c}0.005 \\
\left(.044^{+}\right)\end{array}$ & $\begin{array}{c}0.007 \\
\left(.043^{*}\right)\end{array}$ & $\begin{array}{r}0.009 \\
\left(.041^{*}\right.\end{array}$ \\
\hline Efd(pu) & 1.803 & $\cdot$ & 1.761 & . & . & - & 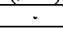 & . \\
\hline $\operatorname{Tm}(\mathrm{pu})$ & 1.003 & 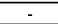 & 1.003 & - & - & - & - & - \\
\hline$\delta(\operatorname{deg})$ & 50.71 & - & 50.64 & . & 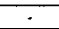 & - & . & . \\
\hline slip & 0.0 & $-1.09 \%$ & 0,0 & $-1.05 \%$ & $-0.99 \%$ & $-0.93 \%$ & $-0.87 \%$ & $-0.81 \%$ \\
\hline$V_{\mathrm{w}}(\mathrm{m} / \mathrm{s})$ & 0.0 & 11.797 & 0. & 11.795 & 11.525 & 11.257 & 10.99 & 10.723 \\
\hline $\mathfrak{B}(\operatorname{deg})$ & - & 0 & - & 0 & 0 & 0 & 0 & 0 \\
\hline
\end{tabular}

Table 2. Generator parameters

Table 3. Initial conditions of generators and turbines

* Reactive power drawn by induction generator. 


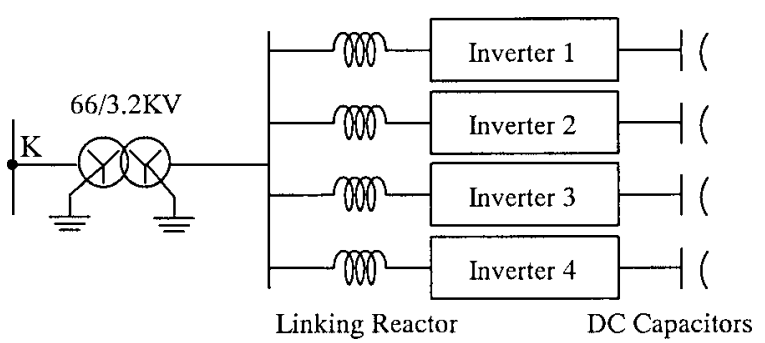

Fig. 9. Schematic diagram of STATCOM design

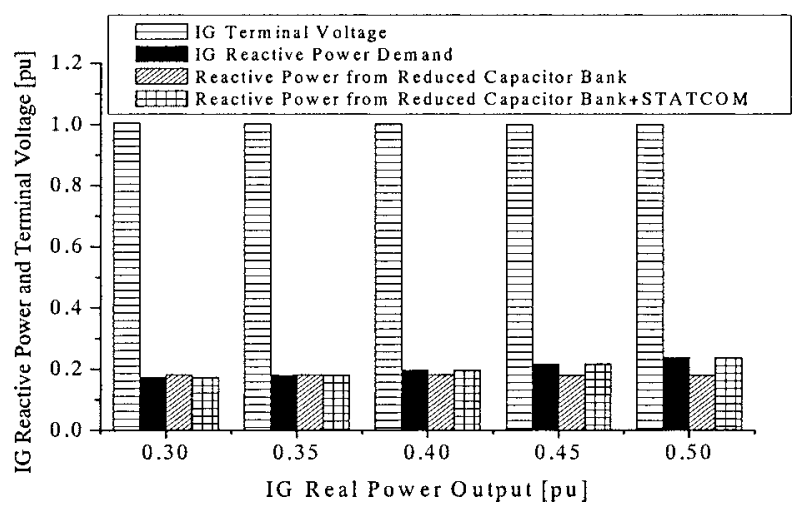

Fig. 10. Steady state characteristics with STATCOM

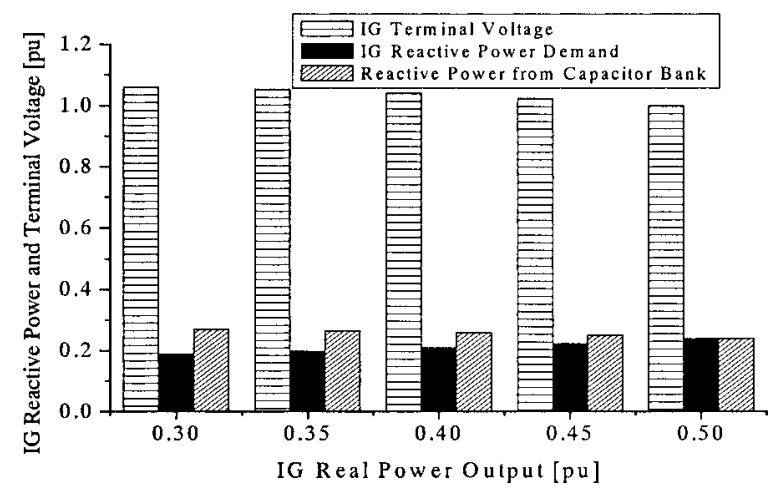

Fig. 11. Steady state characteristics without STATCOM

transient performances of STATCOM are analyzed in the following sections.

4.1 Steady State Analysis In this work, the capacitor bank used for STATCOM controlled wind generator is reduced 20 percentage from its rated capacity (i.e., from $53340 \mu \mathrm{F}(0.239 \mathrm{pu})$ to $42672 \mu \mathrm{F}(0.191 \mathrm{pu}))$. The rest of the reactive power demand of induction generator is supplied by the STATCOM at steady state. The capacitor bank capacity can be reduced further by increasing the continuous rating of STATCOM, depending on the cooling system and some other practical aspects. In Fig. 10 and Fig. 11 the steady state reactive power demand and the corresponding IG terminal voltage are shown at different IG output power with and without considering STATCOM respectively. It is clear that STATCOM can maintain the terminal voltage at rated value at different generated power levels even though the capacitor bank capacity is reduced by a certain percentage.

4.2 Transient Performance of WTGS with STATCOM For simulation purpose symmetrical three- line-toground (3LG) fault or unsymmetrical single-line-to-ground (1LG) fault is considered to occur at point F in Fig. 6. The

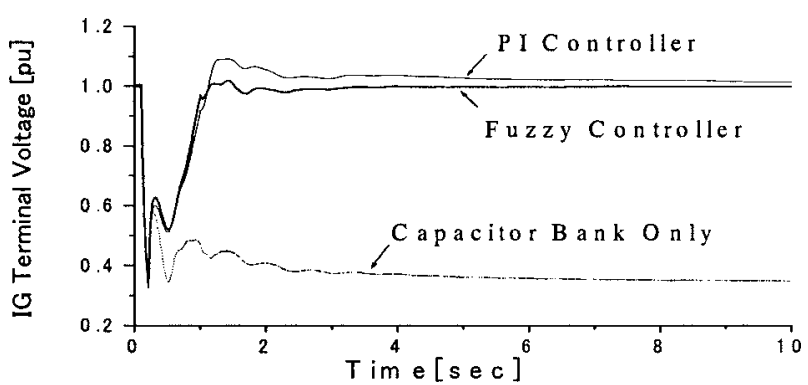

Fig. 12. Terminal voltage of induction generator with \& without STATCOM (Condition1, one-mass, 3LG)

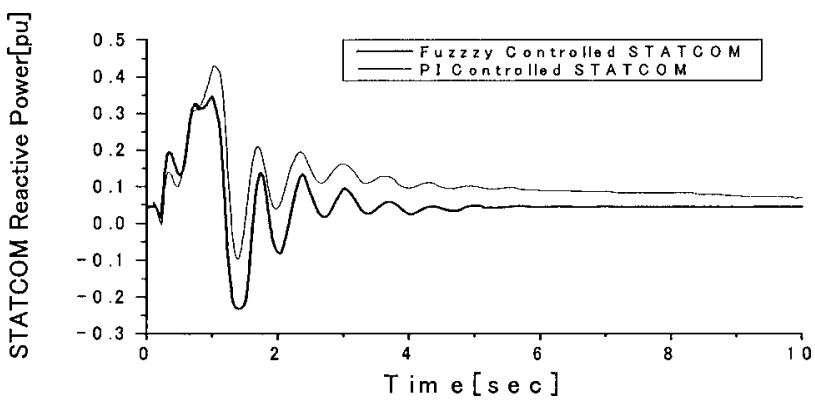

Fig. 13. Reactive power output of STATCOM (Condition1, one-mass, 3LG)

fault occurs at $0.1 \mathrm{sec}$, the circuit breakers (CB) on the faulted line are opened at $0.2 \mathrm{sec}$, and at $1.0 \mathrm{sec}$, the circuit breakers are closed. The simulation time step and total simulation time are chosen $0.0001 \mathrm{sec}$ and $10 \mathrm{sec}$ respectively. Wind speed, $\mathrm{V}_{\mathrm{w}}$, is assumed at rated speed (constant) during the simulation time as shown in Table 3 (condition1). Simulations have been done by PSCAD/EMTDC ${ }^{(30)}$. The steady state error and oscillation of responses are selected as the performance criteria for transient stability evaluation.

4.2.1 One-mass lumped model of WTGS When a severe network disturbance occurs, the fixed capacitor bank with rated capacity value cannot compensate the reactive power demand of induction generator. So, the terminal voltage falls and the generator goes out of step. But if STAT$\mathrm{COM}$ is used, it can provide the necessary reactive power demand and the induction generator doesn't go out of step. Fig. 12 and Fig. 13 show simulation results of the terminal voltage of induction generator and reactive power output of STATCOM respectively during 3LG fault, which have been obtained using one-mass shaft model of WTGS. It is clear that STATCOM can enhance the transient stability of WTGS. Moreover, it is seen that STATCOM equipped with FLC can minimize the overshoot and steady state error of IG terminal voltage than that with conventional PI controller.

4.2.2 Two-mass shaft model of WTGS In Ref. (23), it is reported that the shaft modeling has a significant effect on the transient stability analysis of WTGS. In this work, it is investigated that two-mass shaft model has a significant effect on reactive power compensation of WTGS by using STATCOM. In Fig. 12 we observed that IG can be compensated with reactive power demand by STATCOM after a 3LG fault even when IG is generating rated output power $(50 \mathrm{MW})$. But two-mass shaft model is considered here instead of one mass lumped model. Responses of the IG terminal voltage, IG rotor speed, turbine speed and STATCOM 


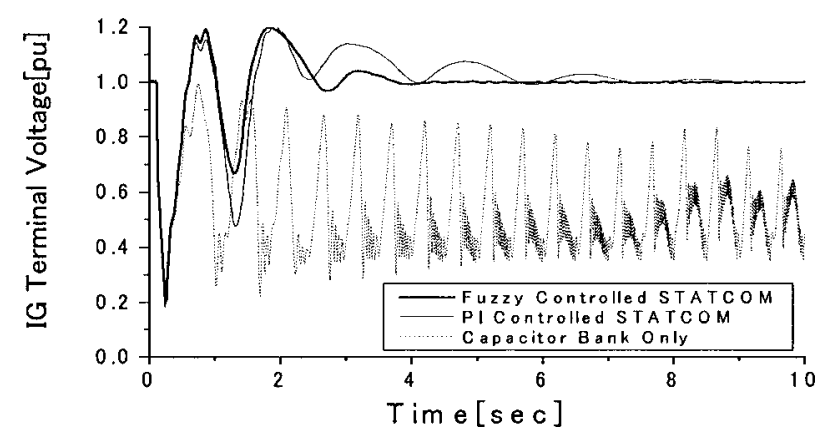

Fig. 14. Terminal voltage of induction generator with \& without STATCOM (Condition1, two-mass, 3LG)

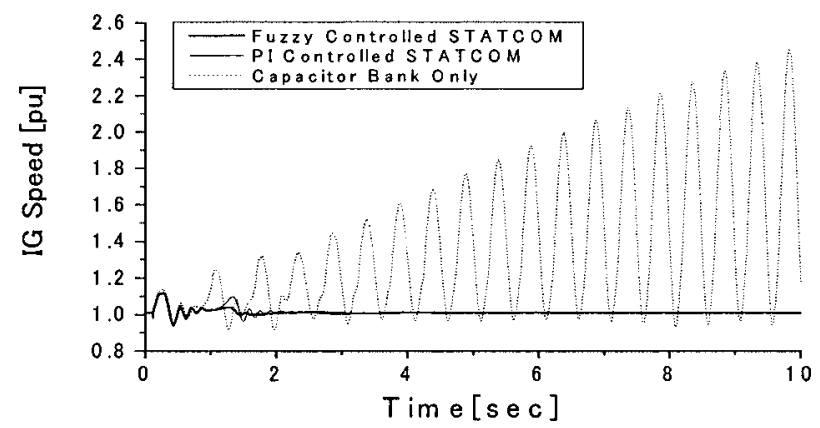

Fig. 15. Rotor speed of induction generator with \& without STATCOM (Condition1, two-mass, 3LG)

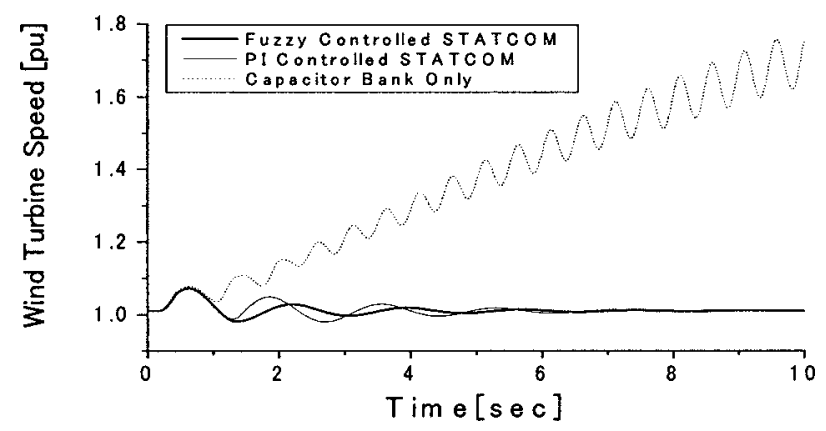

Fig. 16. Wind Turbine speed with \& without STATCOM (Condition1, two-mass, 3LG)

reactive power output are shown in Fig. 14, Fig. 15, Fig. 16, and Fig. 17 respectively. It is noticeable from Fig. 13 and Fig. 17 that STATCOM needs to supply more reactive power for two-mass WTGS compared to one-mass WTGS to compensate the reactive power demand of IG when a network disturbance occurs. Care must be taken when PI and FLC parameters are chosen for multi-mass WTGS. In this case also STATCOM equipped with FLC gives better performance than that with PI controller from the view point of faster recovery of terminal voltage and low rotor oscillation. The load angle of synchronous generator is presented in Fig. 18. It is clear that STATCOM can not only enhance the transient performance of wind generator (for both one-mass and twomass), but also enhance the stability of synchronous generator, i.e. the entire power system.

Both PI and fuzzy parameters are set based on the most severe three-line-to-ground fault. With those sets of parameters, the WTGS becomes stable also under other types of unsymmetrical fault conditions and even at randomly varying wind condition (section-4.3), which validates the

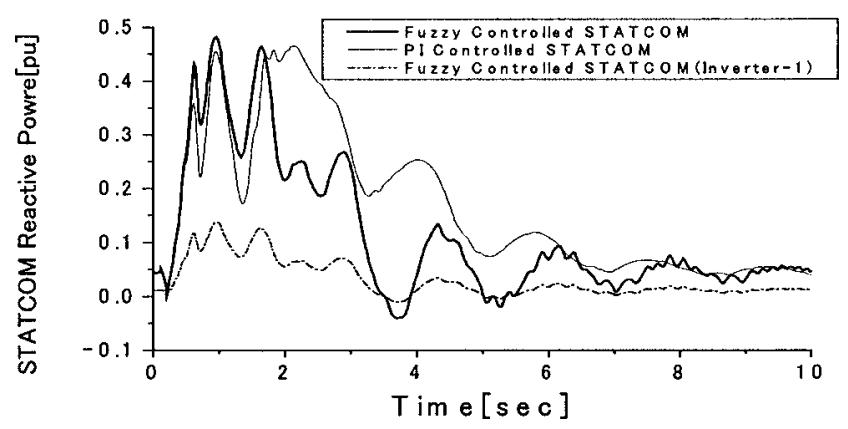

Fig. 17. Reactive power output of STATCOM (Condition1, two-mass, 3LG)

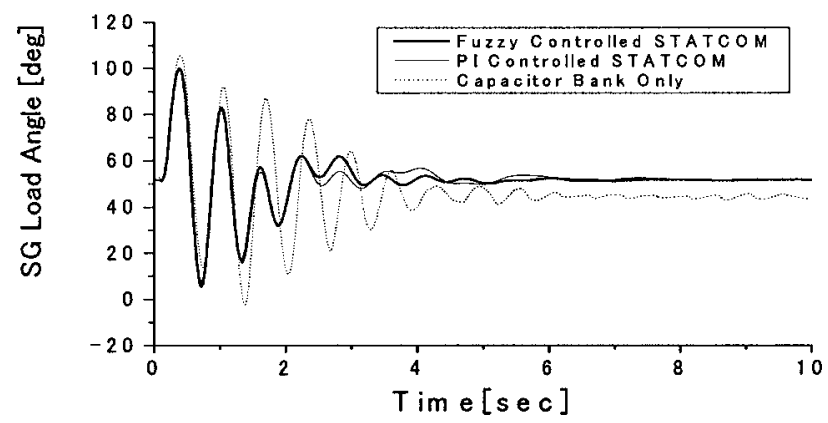

Fig. 18. Load angle of synchronous generator with \& without STATCOM (Condition1, two-mass, 3LG)

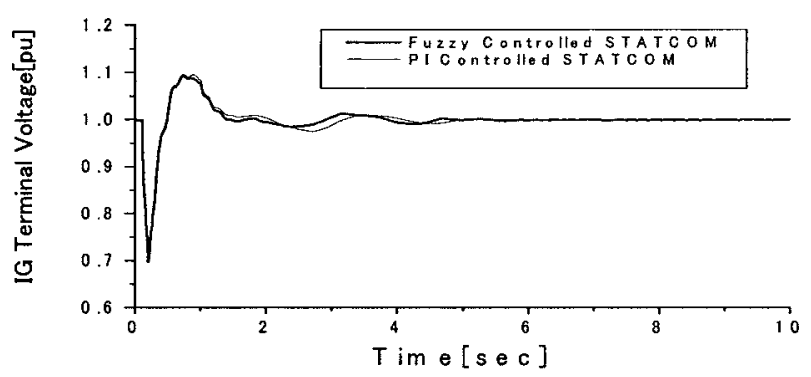

Fig. 19. Terminal voltage of induction generator with \& without STATCOM (Condition1, two-mass, 1LG)

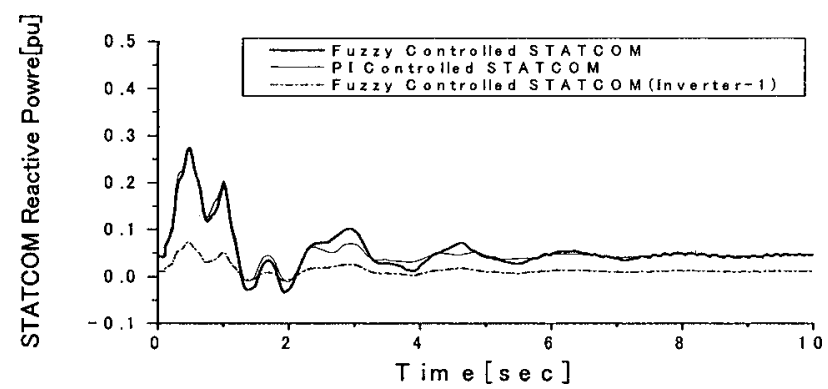

Fig. 20. Reactive power output of STATCOM (Condition1, two-mass, 1LG)

sub-optimality of the constant settings. The responses of IG terminal voltage and STATCOM reactive power for 1LG fault are shown in Fig. 19 and Fig. 20 respectively.

It is ensured that the STATCOM capacity of each inverter module doesn't exceed the rated value under network disturbance as shown in Fig. 17 and Fig. 20. The GTO's voltage and current ratings are maintained also. It is needed to mention that due to the low shaft stiffness of WTGS, the IG rotor and turbine speed cannot increase or decrease instantly. If 


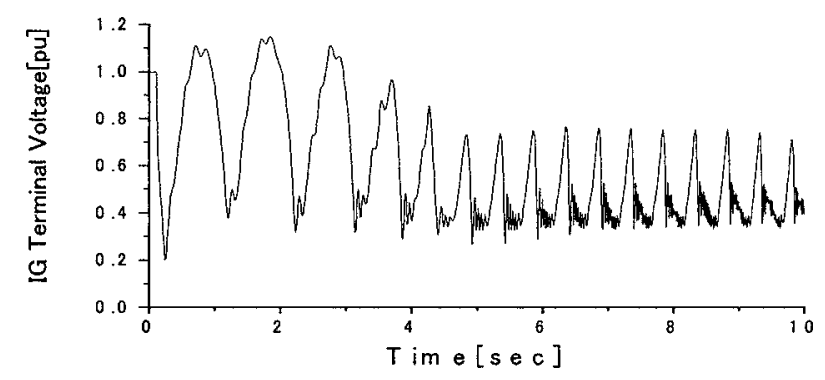

Fig. 21. Terminal voltage of induction generator with STATCOM (Condition1, two-mass, 3LG, unstable case)

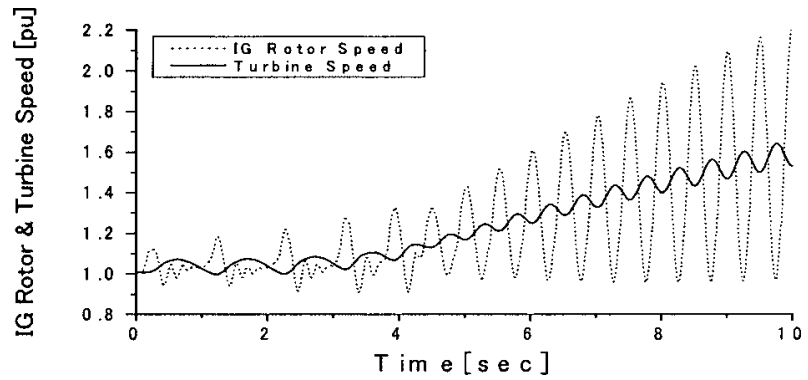

Fig. 22. IG rotor and wind turbine speed with STATCOM (Condition1, two-mass, 3LG, unstable case)

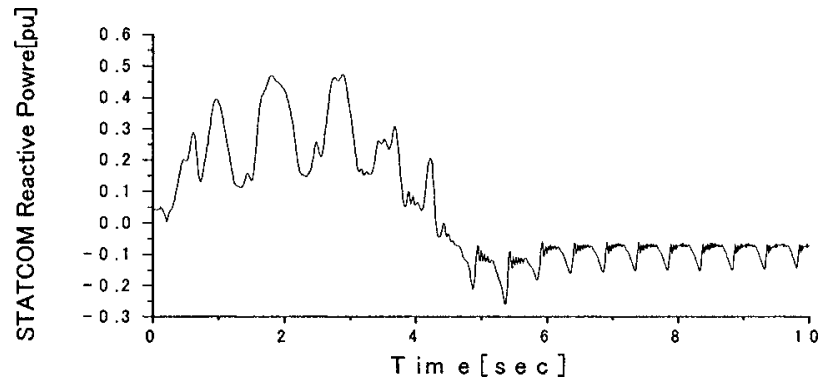

Fig. 23. Reactive power output of STATCOM (Condition1, two-mass, 3LG, unstable case)

immediately after the clearance of the fault, adequate reactive power is not supplied from the STATCOM for the compensation of the IG reactive power demand, the sufficient electromagnetic torque cannot be developed. As a result, the IG rotor speed starts to increase and the IG goes out of step, which can be understood clearly from the terminal voltage, rotor and turbine speeds, and STATCOM reactive power as shown in Fig. 21, Fig. 22, and Fig. 23 respectively. In this situation, the value of $K_{\delta}$ is chosen 0.012 . Therefore, the controller parameters of STATCOM is needed to design carefully based on the most severe fault conditions with appropriate STATCOM ratings, not to exceed the voltage and current ratings of GTO devices.

4.2.3 STATCOM with pitch controller In Ref. (22), the pitch controlled one-mass WTGS was compared with STATCOM controlled WTGS from the point of view of transient stability of WTGS. In this section pitch controlled WTGS $^{(23)}$ is compared with STATCOM controlled WTGS in which the two-mass shaft model is used. Fuzzy logic controlled STATCOM is considered here only. The terminal voltage of induction generator during $3 \mathrm{LG}$ fault as shown in Fig. 24 clearly shows that STATCOM controlled WTGS is transiently more stable than pitch controlled WTGS. If both

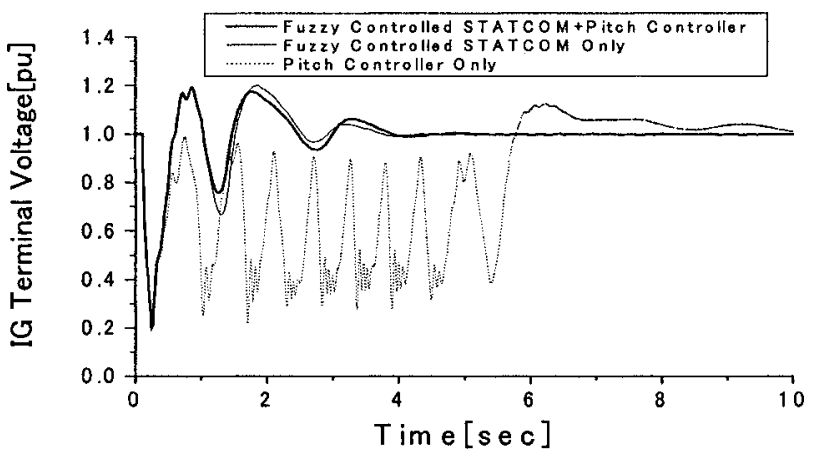

Fig. 24. Terminal voltage of induction generator with STATCOM and pitch controller (Condition1, two-mass, 3LG)

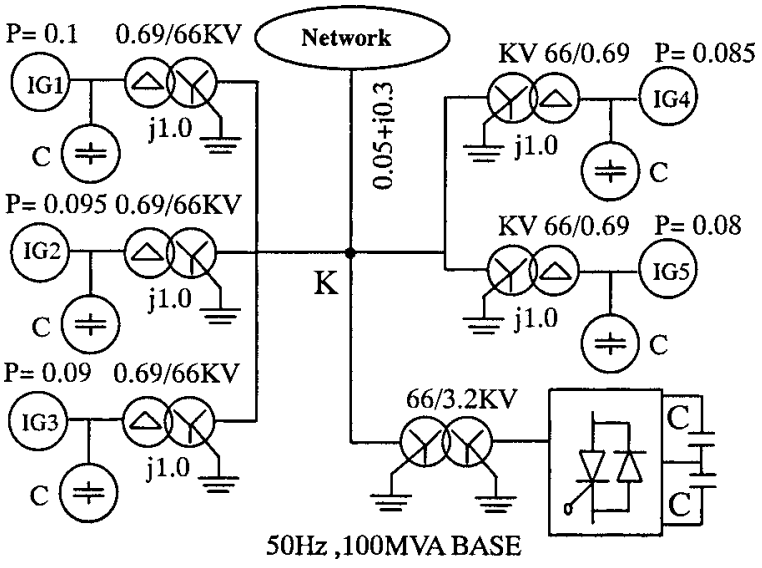

Fig. 25. Wind park and STATCOM

pitch controller and STATCOM are operated together, more good performance can be obtained.

4.2.4 Wind park and STATCOM In the previous sections, we considered the equivalent single WTGS model. But in this section, STATCOM performance is analyzed with considering a wind park model including multiple wind generators for the sake of precise analysis. Replacing the 50 MVA wind generator by five $10 \mathrm{MVA}$ wind generators in Fig. 6, a model system shown in Fig. 25 is obtained. Twomass shaft model is also considered here. The capacitor bank rated capacity is reduced 20 percent at each wind generator terminal when STATCOM is used in the simulation. The initial values used in this case are taken from condition 2 of Table 3. When STATCOM is used with a wind farm, the terminal voltage, $\mathrm{V}_{\mathrm{t}}$, of point $\mathrm{K}$ is used as the input to STATCOM shown in Fig. 4. For simulation analysis only the FLC controlled STATCOM is considered. The IG terminal voltages during 3LG fault without and with STATCOM are shown in Fig. 26 and Fig. 27, respectively. It is seen that STATCOM can compensate the reactive power demand of all generators as shown in Fig. 28. IG terminal voltages can return to their pre-fault values, even if the 20 percentage reduced capacitor bank is used at each IG terminal. But when the STATCOM is not used, rated capacitor bank at each IG terminal cannot make the wind park stable.The synchronous generator load angle are shown in Fig. 29. Besides the wind park, STATCOM can also maintain the load angle of synchronous generator. Therefore, the stability of entire power system is increased. 


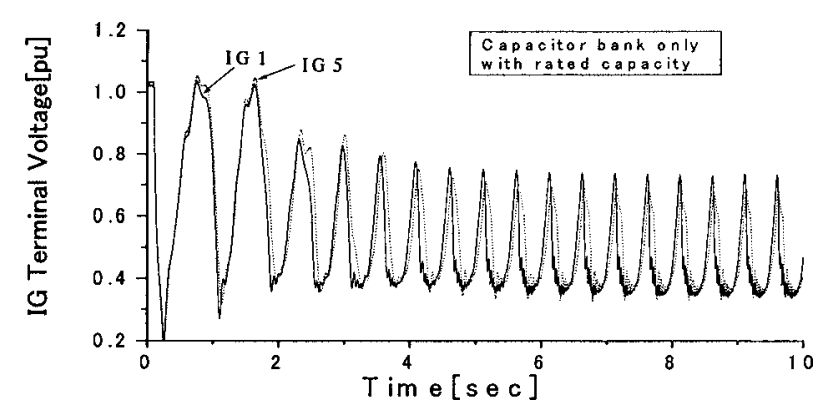

Fig. 26. Terminal voltages of induction generators without STATCOM (Condition2, two-mass, 3LG)

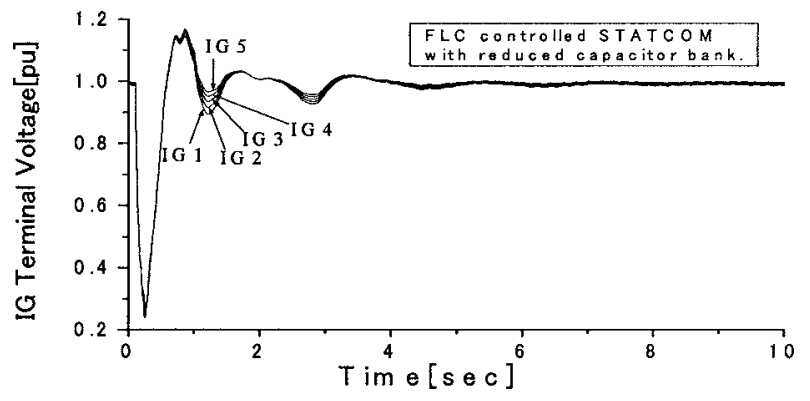

Fig. 27. Terminal voltages of induction generators with STATCOM (Condition2, two-mass, 3LG)

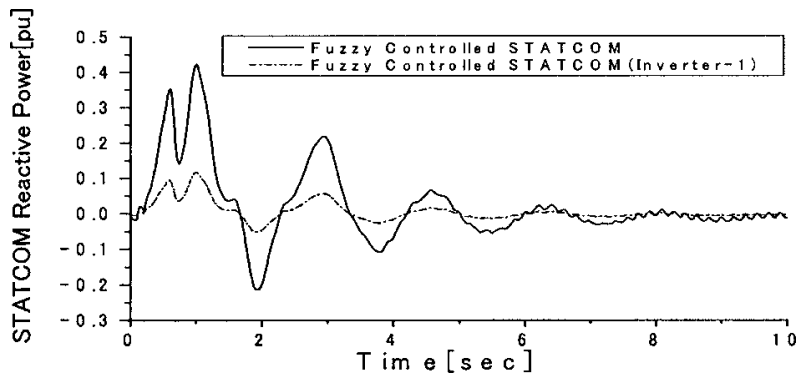

Fig. 28. Reactive power output of STATCOM (Condition2, two-mass, 3LG)

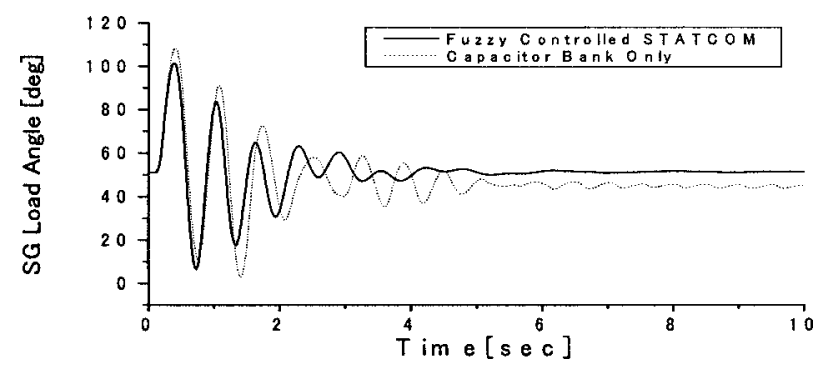

Fig. 29. Load angle of synchronous generator (Condition2, two-mass, 3LG)

4.3 Power Quality Improvement As wind speed is intermittent and stochastic in nature, the generated power from fixed speed wind generator fluctuates randomly. So, the reactive power demand of induction generator is not constant. As a result, only with the rated capacitor bank the induction generator terminal voltage also fluctuates randomly and the power quality of wind generator decreases. Using STATCOM this voltage fluctuation of fixed speed wind generator under randomly varying wind speed can be reduced. The real wind speed data obtained in Hokkaido Island, JAPAN as shown in Fig. 30 is used. Fig. 31 and Fig. 32 shows the

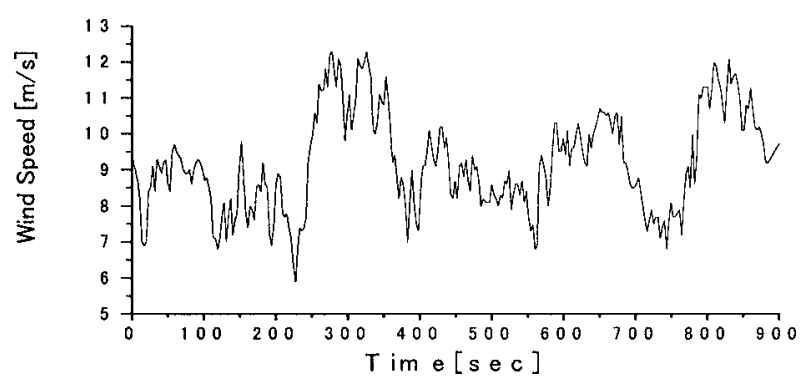

Fig. 30. Hokkaido island wind speed data

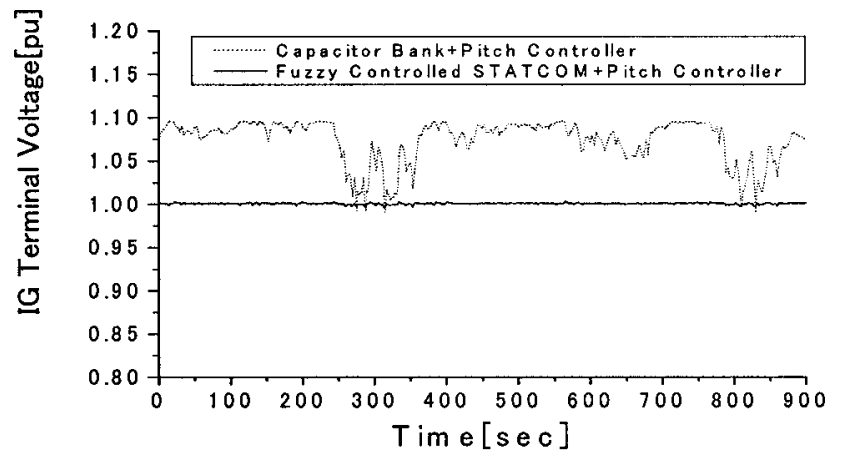

Fig. 31. Terminal voltage of induction generator with and without STATCOM (with FLC) against real wind data

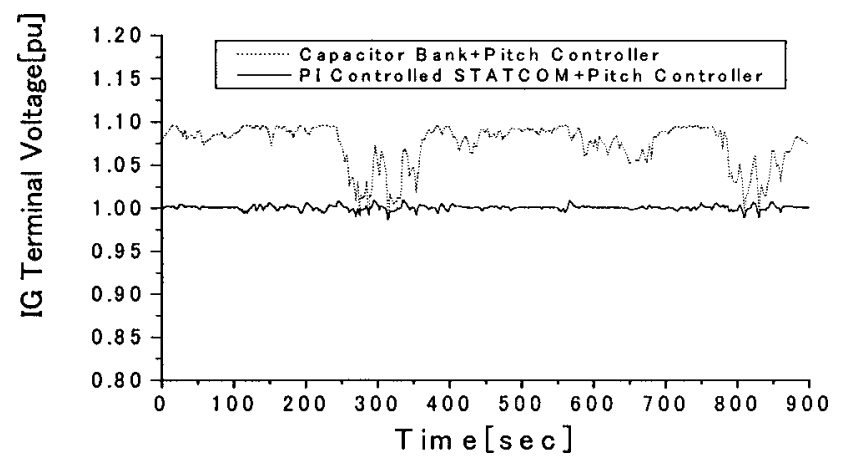

Fig. 32. Terminal voltage of induction generator with and without STATCOM (with PI) against real wind data

terminal voltage response of wind generator under that varying wind speed by using STATCOM equipped with fuzzy or PI controller respectively. It is seen that STATCOM can significantly reduce wind generator voltage fluctuation, i.e. STATCOM can improve the power quality of wind generator. Moreover, it can be observed that the FLC controlled STATCOM can give better smoothness of terminal voltage compared to PI controlled STATCOM. One reason might be that STATCOM equipped with either PI or FLC unit is designed to supply a continuous reactive power at rated wind speed to ensure the rated reactive power supply of IG as capacitor bank capacity is reduced by certain percentages. When the wind speed increases or decreases, this reactive power demand of induction generator increases or decreases respectively. So, the STATCOM reactive power is needed to increase or decrease to maintain the rated terminal voltage. The PI controller cannot do that smoothly compared to FLC controller. 


\section{Conclusions}

In this work, three level VSC based STATCOM is proposed to enhance the steady state and transient performances of WTGS connected with power grid. A simple control strategy of STATCOM is adopted where only measurement of rms voltage at the wind generator terminal is needed. Fuzzy logic controller rather than conventional PI controller is proposed as the control methodology of STATCOM. This study concludes the following points:

(1) FLC controlled STATCOM can significantly improve the transient performance of WTGS after severe network disturbance.

(2) Multi-mass shaft model of WTGS is needed to consider for simulation study as it has a big influence on the transient performance of WTGS.

(3) Transient performance of STATCOM controlled WTGS is better than that of pitch controlled WTGS.

(4) In this study, the steady state performance of STATCOM controlled WTGS is analyzed also. The capacitor bank capacity of wind generator can be reduced by a certain percentage, if STATCOM is connected with WTGS.

(5) It is reported that STATCOM can reduce the voltage fluctuation of wind generator significantly under variable wind speed, i.e. it can improve the power quality of grid connected wind generator.

Finally, it can be concluded that FLC controlled STATCOM can enhance steady state and transient performances of grid connected wind turbine generator system.

(Manuscript received Dec. 15, 2005, revised May 15, 2006)

\section{References}

(1) The European Wind Energy Association, EWEA Publications, 2005, "Wind Force 12-A Blueprint to Achieve $12 \%$ of the World's Electricity From Wind power by 2020", [Online], http://www.ewea.org/ (2005)

( 2 ) C.L. Souza, L.M. Neto, G.C. Guimaraes, and A.J. Moraes: "Power System Transient Stability Analysis Including Synchronous and Induction Generator", IEEE Porto Power Tech Proceedings, Vol.2, p.6 (2001)

( 3 ) Dr. L. Gyugyi: "Unified Power-Flow Control Concept for Flexible AC Transmission Systems", IEE Proc.-C, Vol.139, No.4, pp.323-331 (1992)

( 4 ) L. Gyugyi: "Dynamic Compensation of AC Transmission Lines By SolidState Synchronous Voltage Sources", IEEE Trans. Power Delivery, Vol.9, No.2, pp.904-911 (1994)

( 5 ) H.F. Wang, F. Li, and R.G. Cameron: "Facts Control Design Based on Power System Nonparametric Models", IEE Proc.-Gener. Transm. Distrib., Vol.146, No.5, pp.409-415 (1999)

( 6 ) L. Cong, Y. Wang, and D.J. Hill: "Transient Stability and Voltage Regulation Enhancement Via Coordinated Control of Generator Excitation and SVC', Electrical Power \& Energy Syst., Vol.27, pp.121-130 (2005)

( 7 ) T. Ahmed, O. Noro, E. Hiraki, and M. Nakaoka: "Terminal Voltage Regulation Characteristics by Static Var Compensator for a Three-Phase SelfExcited Induction Generator", IEEE Trans. Industr. Applic., Vol.40, No.4, pp.978-988 (2004)

( 8 ) Y.L. Tan: "Analysis of Line Compensation by Shunt-Connected FACTS Controllers: A Comparison between SVC and STATCOM", IEEE Power Engineering Rev., pp.57-58 (1999)

(9) K.R. Padiyar and A.M. Kulkarni: "Design of Reactive Current and Voltage Controller of Static Condenser", Electric Power \& Energy Syst., Vol.19, No.6, pp.397-410 (1997)

(10) C.K. Sao, P.W. Lehn, M.R. Iravani, and J.A. Martinez: "A Benchmark System for Digital Time-Domain Simulation of a Pulse-Width- Modulated D-STATCOM", IEEE Trans. Power Delivery, Vol.17, No.4, pp.1113-1120 (2002)
(11) G.W. Moon: "Predictive Current Control of Distribution Static Compensator for Reactive Power Compensation", IEE Proc. Gener. Transm. Distrib., Vol.146, No.5, pp.515-520 (1999)

(12) H.F. Wang: "Phillips-Hoffron Model of Power Systems Installed with STATCOM and Applications", IEE Proc.-Gener. Transm. Distrib., Vol.146, No.5, pp.521-527 (1999)

(13) C. Schauder, M. Gernhardt, E. Stacey, T. Lemak, L. Gyugyi, T.W. Cease, and A. Edris: "Development of a \pm 100 MVAR Static Condenser for Voltage Control of Transmission Systems", IEEE Trans. Power Delivery, Vol.10, No.3, pp.1486-1496 (1995)

(14) O. Anaya-Lara and E. Acha: "Modeling and Analysis of Custom Power System by PSCAD/EMTDC", IEEE Trans. Power Delivery, Vol.17, No.1, pp.266-272 (2002)

(15) G.C. Cho, G.H. Jung, N.S. Choi, and G.H. Cho: "Analysis and Controller Design of Static Var Compensator Using Three-Level GTO Inverter", IEEE Trans. Power Electron., Vol.11, No.1, pp.57-65 (1996)

(16) M.I. Mazurov, A.V. Nikolaev, and N.G. Lozinova: "Improvement of Voltage Quality in AC Network by use of STATCOM", IEEE PowerTech 2005, Russia (2005)

(17) J.B. Ekanayake and N. Jenkins: "Mathemetical Models of a three-level advanced static VAR Compensator", IEE Proc.-Gener. Transm. Distrib., Vol.144, No.2, pp.201-206 (1997)

(18) Z. Daad-Saoud: "Application of STATCOMs to Wind Farms", IEE Proc. Gener. Transm. Distrib. Vol.145, No.5, pp.511-517 (1998)

(19) Z. Chen, F. Blaabjerg, and Y. Hu: "Voltage Recovery of Dynamic Slip Control Wind Turbines with a STATCOM", International Power Electronic Conference (IPEC05), S29-5, pp.1093-1100 (2005)

(20) T. Sun, Z. Chen, and F. Blaabjerg: "Flicker Mitigation of Grid Connected Wind Turbines Using STATCOM", Proc. of $2^{\text {nd }}$ IEE International Conference on Power Electronics, Machines and Drives, PEMD04 (2004)

(21) T. Larsson and C. Poumarede: "STATCOM, an Efficient Means for Flicker Mitigation", Proc. of IEEE Power Engineering Society 1999 Winter Meeting, pp.1208-1213, New York, USA (1999)

(22) S.M. Muyeen, M.A. Mannan, M.H. Ali, R. Takahashi, T. Murata, and J. Tamura: "Stabilization of Grid Connected Wind Generator by STATCOM", International Conference on Power Electronics and Drive Systems (IEEE PEDS 2005), Conference CDROM, pp.1584-1589, Malaysia (2005)

(23) S.M. Muyeen, M.A. Mannan, M.H. Ali, R. Takahashi, T. Murata, J. Tamura, Y. Tomaki, A. Sakahara, and E. Sasano: "Transient Stability Analysis of Wind Generator System with the Consideration of Multi-Mass Shaft Model", International Conference on Power Electronics and Drive Systems (IEEE PEDS 2005), Conference CDROM, pp.511-516, Malaysis (2005)

(24) S.K. Salman and A.L.J. Teo: "Improvement of Fault Clearing Time of Wind Farm Using Reactive Power Compensation", 2001 IEEE Porto Power Tech Proceedings, Vol.4, SSR2-097 (2001)

(25) P.M. Anderson and A. Bose: "Stability Simulation of Wind Turbine Systems", IEEE Trans. Power Apparatus Syst., Vol.PAS-102, No.12, pp.37913795 (1983)

(26) S.K. Salman and A.L. Teo: "Windmill Modeling Consideration and Factors Influencing the Stability of a Grid-Connected Wind Power-Based Embedded Generator", IEEE Trans. Power Syst., Vol.18, No.2, pp.793-802 (2003)

(27) Y. Shima, R. Takahashi, T. Murata, J. Tamura, Y. Tomaki, S. Tominaga, and A. Sakahara: "Transient Stability Simulation of Wind Generator Expressed by Two-Mass Model", IEEJ Trans. PE, Vol.125-B, No.9, pp.855-864 (2005)

(28) S.M. Muyeen, M.H. Ali, R. Takahashi, T. Murata, J. Tamura, Y. Tomaki, A Sakahara, and E. Sasano: "Transient Stability Analysis of Grid Connected Wind Turbine Generator System Considering Multi-Mass Shaft Modeling", Accepted to Publish in Electric Power Components \& Systems, Vol.34, No.10 (2006)

(29) D. Driankov, H. Hellendoorn, and M. Reinfrank: An Introduction to Fuzzy Control, Springer-Verlag (1993)

(30) PSCAD/EMTDC Manual, Manitoba HVDC Research Center (1994)

S. M. Muyeen (Student Member) He was born in Khulna, Bangladesh

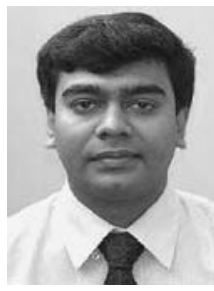
on September 08, 1975. He received his B.Sc. Eng. Degree from Rajshahi University of Engineering and Technology (RUET), Bangladesh and M.Sc. Eng. Degree from Kitami Institute of Technology, Japan, in 2000 and 2005 respectively, all in Electrical and Electronic Engineering. Presently he is working towards his Ph.D. degree at the Kitami Institute of Technology, Japan. His research interests are, wind generator stability analysis, FACTS devices, and multi-mass drive train of wind turbine. 
Mohammad Abdul Mannan (Student Member) He was born in

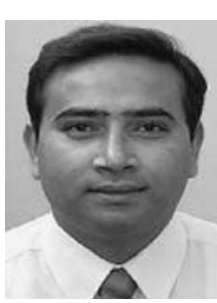
Laxmipur, Bangladesh on January 01, 1975. He received his B.Sc. Eng. Degree from Bangladesh Institute of Technology (BIT)-Rajshahi, Bangladesh and M.Sc. Eng. Degree from Kitami Institute of Technology, Japan, in 1998 and 2003 respectively, all in Electrical and Electronic Engineering. Presently he is working towards his Ph.D. degree at the Kitami Institute of Technology, Japan. His research interests are in the areas of electrical machines, power electronics, power systems, and applications of different controller and observer systems to electrical machines.

Mohd. Hasan Ali (Member) He received his B.Sc. Eng. Degree from

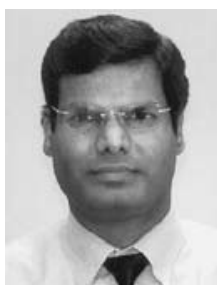
Rajshahi University of Engineering and Technology (RUET), Bangladesh in 1995 and M.Sc. Eng. and Dr. Eng. Degrees from Kitami Institute of Technology, Japan, in 2001 and 2004 respectively, all in Electrical and Electronic Engineering. He is an Assistant Professor in EEE dept. of RUET, Bangladesh. Presently he is doing research works under the JSPS Postdoctoral Fellowship Program at the Kitami Institute of Technology, Japan. He is a member of the IEB, the IEE of Japan and the IEEE Power Engineering Society.

Rion Takahashi (Member) He received the B. degree in electrical and

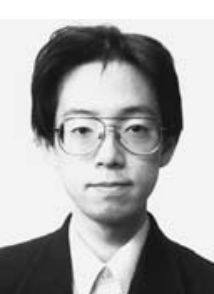
electronic engineering from Kitami Institute of Technology, Japan in 1998. Now he is research assistant in Department of Electric and Electronic Engineering, Kitami Institute of Technology. His major research interests include analysis of power system transient, wind energy conversion system.
Toshiaki Murata (Member) He completed his Electrical Engineer-

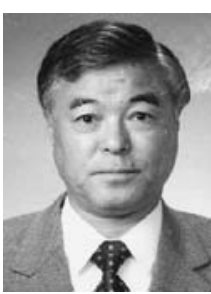
ing Curriculum of the Teacher Training School from Hokkaido University, Japan. Since 1969, he had been a Research Assistant at the Kitami Institute of Technology, Japan. He received Dr. Eng. degree from Hokkaido University in 1991. Presently he is an associate professor at the Kitami Institute of Technology.

Junji Tamura (Member) He received his B.Sc. Eng. Degree from

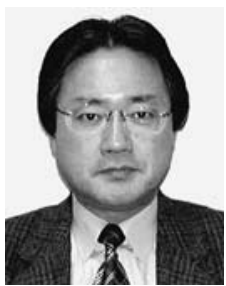
Muroran Institute of Technology, Japan, in 1979 and M.Sc. Eng. and Dr. Eng. degrees from Hokkaido University, Japan, in 1981 and 1984 respectively, all in electrical engineering. In 1984, he became a lecturer and in 1986, an associate professor at the Kitami Institute of Technology, Japan. Currently he is a professor at the Kitami Institute of Technology. He is the senior member of IEEE. 